\title{
AN ECTOPIC UNERUPTED TOOTH IN MAXILLARY SINUS
}

Sushil Kumar Kashyap ${ }^{1}$, Ravindra Kumar², Sushil Kumar ${ }^{3}$

\section{HOW TO CITE THIS ARTICLE:}

Sushil Kumar Kashyap, Ravindra Kumar, Sushil Kumar. "An Ectopic Unerupted Tooth in Maxillary Sinus". Journal of Evolution of Medical and Dental Sciences 2014; Vol. 3, Issue 02, January 13; Page: 446-449, DOI:10.14260/jemds/2014/1847

ABSTRACT: OBJECTIVE: We report a rare case of ectopic unerupted tooth in maxillary sinus. CASE REPORT: A 23 year old female presented with oroantral fistula distal to right upper second molar. On radiography, there was an ectopic unerupted tooth in maxillary sinus, removed via sublabial approach with sinuscope. CONCLUSION: This is a rare case of unerupted ectopic tooth in maxillary sinus that presented with oroantral fistula. Opacity in maxillary sinus may be due to unerupted ectopic tooth. Complete removal of tooth along with associated mucosal disease of sinus by Caldwell luc (sublabial) approach with sinuscope is curative.

KEY WORDS: Ectopic tooth; Unerupted tooth; maxillary sinus.

INTRODUCTION: Tooth development results from a complicated multi-step interaction between the oral epithelium and the underlying mesenchymal tissue. A series of complex tissue interactions result in the formation of mature teeth. Abnormal tissue interaction during development may potentially result in ectopic tooth development and eruption.

Ectopic eruption of a tooth into the dental environment is common, whereas ectopic eruption of a tooth in other sites is rare. Diverse oral anatomical locations can infrequently be the site of an ectopic tooth eruption. Such locations include the nasal cavity, chin, mandibular condyle, coronoid process. One of the sites for an ectopic tooth in a no dental location is the maxillary sinus. Tooth in the maxillary sinus is rare. Due to its rarity, the literature that deals with this is sparse. Ectopic eruption may be associated with one of three distinct processes, Developmental disturbances, pathological processes and iatrogenic activity. The etiology of ectopic teeth is not always known.

Impaction of a tooth in the maxillary sinus can be asymptomatic. Such teeth are often discovered serendipitously on radiographs of the skull or teeth. In some cases, patients experience significant symptoms like sinonasal symptoms, oroantral fistula etc. Tooth eruption in the maxillary sinus may cause sinusitis. The treatment of an ectopic maxillary tooth is surgical removal. We present a case of an ectopic third molar which presented in the maxillary sinus presented as oro antral fistula and was removed via endoscopic surgery.

CASE REPORT: A 23 years old healthy female was presented for evaluation of pus discharging oro antral fistula distal to right upper second molar. The intra oral examination revealed the right upper third molar was absent. Purulent material from the oro antral fistula was observed. The extra oral examination revealed no signs or symptoms. The patient complained of a headache on the right side of his face for approximately 3 - 4 years. The Xray PNS water's view (figure 1) and lateral view of face (figure 2), and orthopentogram (figure 3) showed a well - defined circular opacity surrounded by a soft tissue mass in the right maxillary sinus. Computed tomography (CT) of 
the para nasal sinuses (figure 4) revealed the presence of an aberrant tooth presumably a third molar.

Operation was performed under general anesthesia. The ectopic tooth was removed via sublabial approach (Caldwel luc). A small window was made over anterior wall of maxilla. The ectopic tooth was localized and removed with help of 0 degree and 30 degree sinuscope (figure 5) along with diseased mucosa and purulent material (figure 6). Patient's symptoms were resolved.

DISCUSSION: The etiology of ectopic eruption is still unclear and many theories have been suggested including trauma, infection, cyst, tumor, overcrowding, and developmental abnormalities. ${ }^{1}$ Presumably the etiologic factor is related to the type of tooth and its immediate anatomic environment. In the present case the right upper third molar was absent from its normal position and was found in the right maxillary sinus.

In such cases the teeth can migrate to various locations including the maxillary sinus, nose, and infraorbital area. Ectopic eruption of tooth into regions other than the oral cavity is unusual although there have been reports of teeth in the nasal septum, mandibular condyle, coronoid process, palate, chin, and maxillary sinus. Teeth developing in the maxillary sinus are rare. Patients with this rare dental abnormality are, therefore, more likely to be managed by medical practitioners than their dental counterparts. The diagnosis of this condition can easily be made radiologically by panoramic radiograph or radiographs of the maxillary sinuses that demonstrate the presence of the highly radiopaque tooth and unusual surrounding soft tissue which is a reaction seen commonly associated with in chronic sinus disease. The opacity of maxillary sinus on x-ray PNS- water's view due to ectopic tooth can be misinterpreted as sinonasal disease so panoramic radiograph may be done before $\mathrm{CT}$ scan. ${ }^{2}$ In the present case, there was an oroantral fistula on right side. On radiography we discovered an ectopic tooth in maxillary sinus antrum. Ectopic teeth in maxillary sinus are radio-opaque and therefore can be easily diagnosed on radiography.

Patients with ectopic tooth impaction in the maxillary sinus can remain asymptomatic over the course of their lifetime. ${ }^{3}$ Some authors reported nasal obstruction, facial fullness, headache, and hyposmia. In the present case the patient complained of an Oro- antral fistula right side with pus discharging from fistula and headache. Occasionally, a tooth may erupt in the maxillary sinus and present with local Sino-nasal symptoms attributed to chronic sinusitis. ${ }^{4}$ Because of the rarity of tooth impaction in the maxillary sinus, the literature on this subject is limited to case reports. Jude et al. reported a case of occlusion of the sinus ostium by an ectopic molar, its location was little higher and medial than it is in our patient. ${ }^{5}$ Elango S., reported a case ectopic tooth in roof of maxillary sinus. ${ }^{6}$ Hasbini A.S. \& Ghafari J., reported a case of ectopic tooth in maxillary sinus obstructing osteomeatal complex which was removed endoscopically. ${ }^{7}$ The removal of unerupted ectopic tooth in maxillary sinus required an unspecified anterior antrostomy, probably a CaldwellLuc approach or a variation there of. ${ }^{8}$ The Caldwell-Luc operation is the standard approach for removing teeth in the sinus. In our patient, the proximity of the third molar to the posterior wall and its height facilitated endoscopic exploration and extraction. Alexandrakis et.al. reported a nasolacrimal duct obstruction secondary to ectopic teeth in two patients. The tooth of one of these patients was extracted endoscopically, and the tooth of the other by the Caldwell-Luc approach. ${ }^{9}$ The sub labial incision was made from lateral incisor to first molar. The canine fossa was exposed and small size window was made on canine fossa. The sinuscope was introduced in maxillary sinus 
antrum and tooth was localized. A bone like substance covering the root of a tooth was also noted. The tooth was dislodged under endoscopic vision. The dislodged ectopic tooth and associated hypertrophied mucosa was extracted through the window made on anterior wall of maxilla. The feasibility of endoscopic removal is related to the ease of endoscopic manipulation in the sinus antrum that facilitated the tooth removal along with visualization of maxillary sinus for associated diseases.

SUMMARY: The treatment of an ectopic tooth in the maxillary sinus is usually surgically removed via the Caldwell-Luc approach with or without the help of sinuscope. The sinuscope gives excellent access and visualization of maxillary sinus antrum for tooth position and associated mucosal disease, so that same can be removed along with Since the ectopic tooth was the cause of oroantral fistula in the present case, so it was removed.
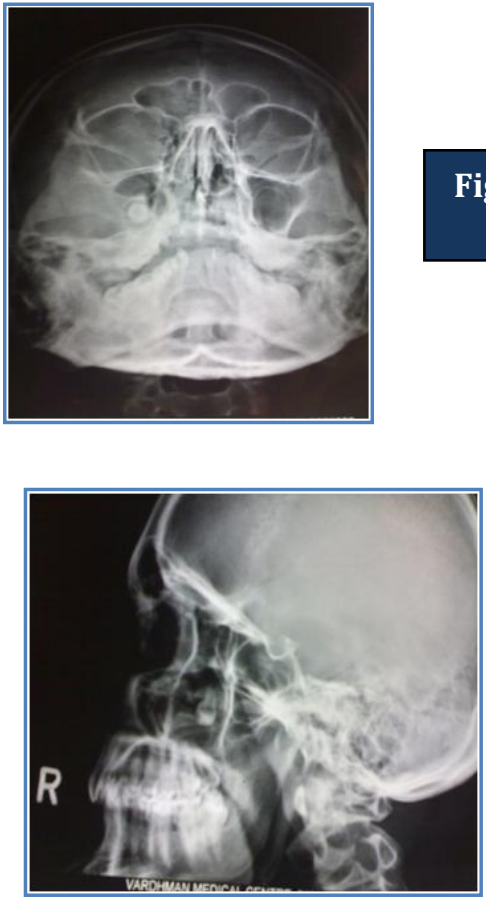

Fig. 2: X ray skul lateral view showing ectopic unerupted tooth in right maxillary sinus.

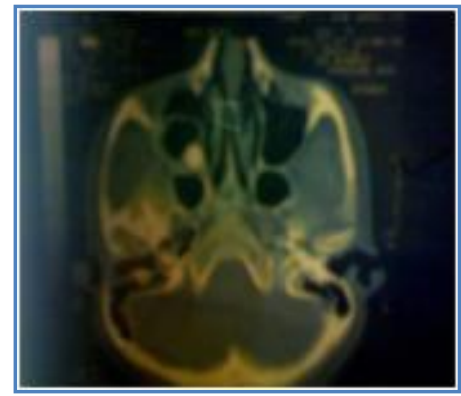

Fig. 4: CT scan, Axial section shows tooth in right maxillary sinus with mucosal hypertrophy.

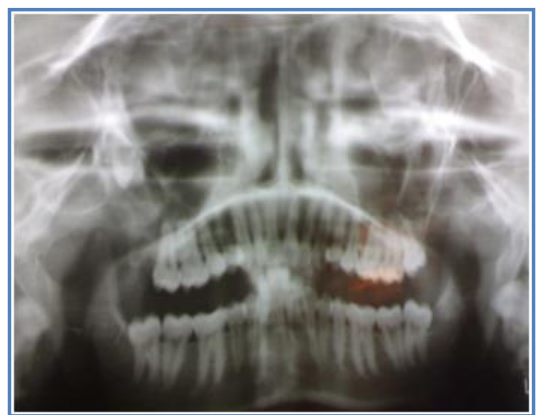

Fig. 3: Orthopentogram showing ectopic unerupted tooth in right maxillary sinus.

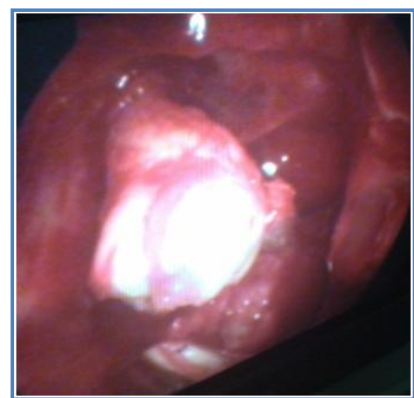

Fig. 5: Endoscopic view of ectopic tooth in maxillary sinus. 


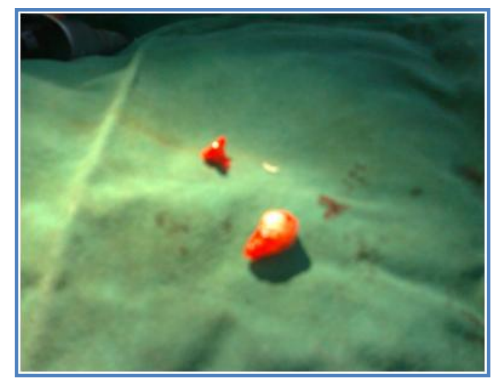

\section{Fig. 6: Showing removed tooth}

from right maxillary sinus.

\section{REFERENCES:}

1. Pracy JP, Williams HO, Montgomery PQ. Nasal teeth; J Laryngol Otol 1992; 106: 366-7.

2. Timucin B, Harun D, Hasan Y, Muqe Cina A. Clinical input of ectopic teeth in the maxillary sinus; International journal of ORL \& head \& neck surgery; Sept 2006; 33(3); 277-81.

3. Goodman W.S. The Caldwell-Luc procedure; Otolaryngol. Clin. North America; 1976; 9:18795.

4. Goh YH. Ectopic eruption of maxillary molar tooth-an unusual cause of recurrent sinusitis; Singapore Med J. 2001 Feb; 42(2):80-1.

5. Jude R, Horowitz J, Loree T. A case report, Ectopic molars that cause osteomeatal complex obstruction; J Am Dent Assoc; 1995: 126:1655-7.

6. Elango S, Palaniappan SP. Ectopic tooth in the roof of the maxillary sinus; Ear Nose Throat J; 1991 Jun; 70(6): 365-6.

7. Hasbini AS, Hadi U, Ghafari J. Endoscopic removal of an ectopic third molar obstructing the osteomeatal complex; Ear Nose Throat J; 2001 Sep; 80(9):667-70.

8. Bodner L, Tovi F, Bar-Ziv J. Teeth in the maxillary sinus--imaging and management; J Laryngol Otol; 1997 Sep; 111(9): 820-4.

9. Alexandrakis G, Hubbell RN, Aitken PA. Nasolacrimal duct obstruction secondary to ectopic teeth; Ophthalmology; 2000 Jan; 107(1): 189-92.

\section{AUTHORS:}

1. Sushil Kumar Kashyap

2. Ravindra Kumar

3. Sushil Kumar

\section{PARTICULARS OF CONTRIBUTORS:}

1. Associate Professor, Department of ENT, MLB Medical College, Jhansi (U.P.), India.

2. Junior Resident, Department of ENT, MLB Medical College, Jhansi (U.P.), India.

3. Junior Resident, Department of ENT, MLB Medical College, Jhansi (U.P.), India.
NAME ADDRESS EMAIL ID OF THE CORRESPONDING AUTHOR:

Dr. Sushil Kumar Kashyap., Associate Professor, Department of ENT,

Flat No. PR/7, MLB Medical College, Jhansi (U.P.), India.

Email-sushiled20@gmail.com

Date of Submission: 14/12/2013.

Date of Peer Review: 16/12/2013.

Date of Acceptance: 27/12/2013.

Date of Publishing: 10/01/2014 